\title{
Application of the Hidden Markov Model for Innovative Projects "Viability" Analysis
}

\author{
Master Thesis \\ Submitted to the \\ Department of Computer Science and Languages at \\ Anhalt University of Applied Sciences \\ in fulfillment of the requirements for the degree of \\ Master of Science \\ Rashidov A.R. \\ (Matr. Nr.:4063178) \\ supervisor: \\ Dr. W. Loch
}

June 2016 


\begin{abstract}
This master thesis deals with determining of innovative projects "viability". "Viability" is the probability of innovative project being implemented. Hidden Markov Models are used for evaluation of this factor. The problem of determining parameters of model, which produce given data sequence with the highest probability, are solving in this research.

Data about innovative projects contained in reports of Russian programs "UMNIK", "START" and additional data obtained during study are used as input data for determining of model parameters.

The Baum-Welch algorithm which is one implementation of expectationmaximization algorithm is used at this research for calculating model parameters.

At the end part of the master thesis mathematical basics for practical implementation are given (in particular mathematical description of the algorithm and implementation methods for Markov models).
\end{abstract}




\section{Contents}

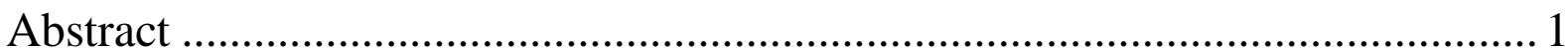

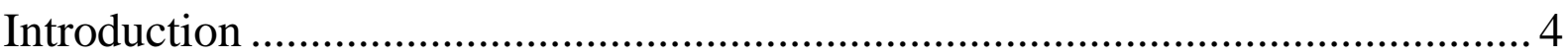

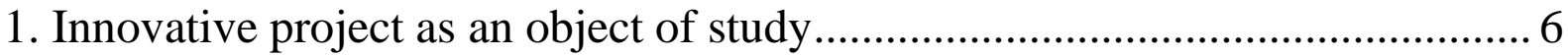

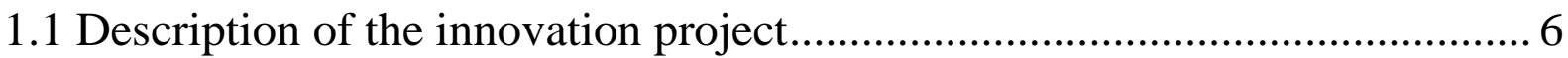

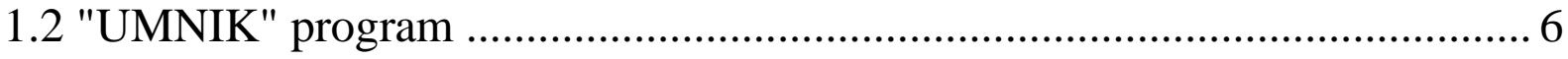

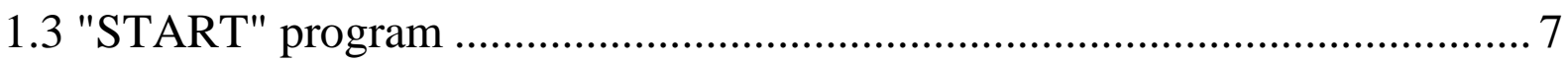

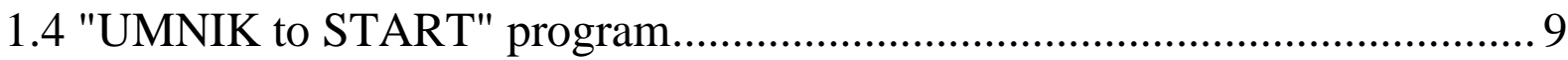

2. Search of method for determining the "viability" of the innovative project .. 10

2.1 Artificial Neural Networks............................................................................... 10

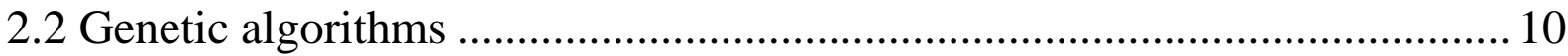

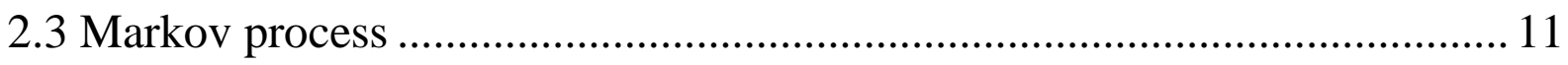

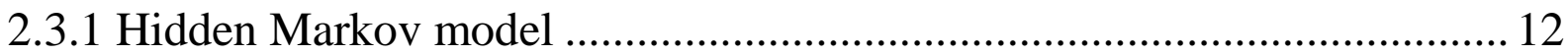

2.4 The use of a hidden Markov model relative to federal programs "UMNIK",

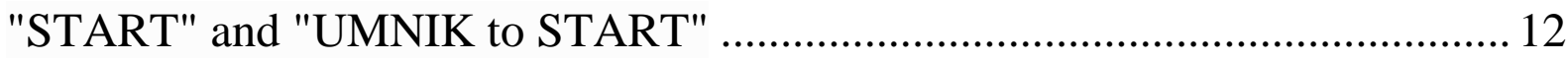

2.5 Search algorithm for finding the unknown parameters of a hidden Markov

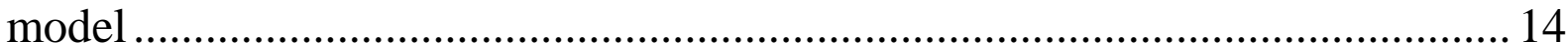

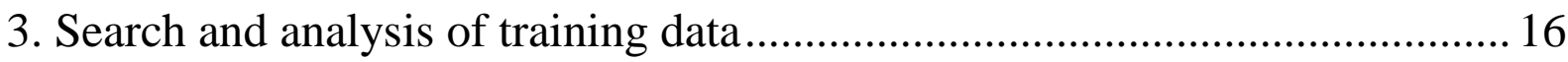

3.1 Search and analysis of the necessary input data ......................................... 16

3.2 Influence criteria of the innovative project at the program stage ................ 18

4. Practical implementation of the Markov model and the calculation of

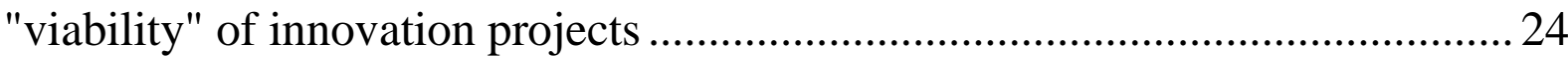

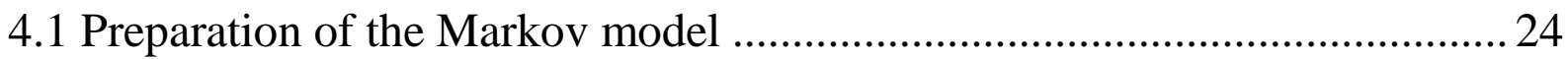

4.2 Implementation of Markov model ............................................................... 26

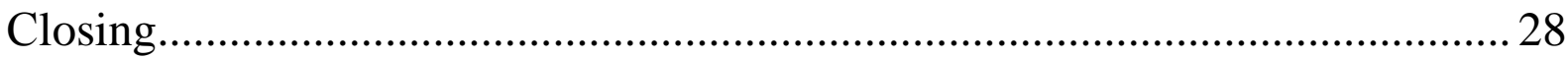

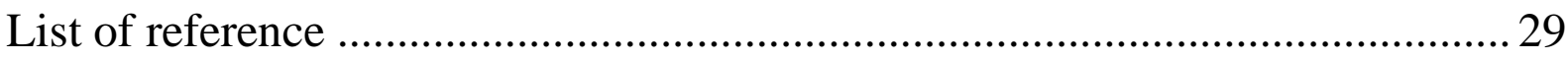




\section{Introduction}

Nowadays, there are many innovative projects in different fields of science. Some of them do not find the application and implementation.

Innovative project (IP) is a complex system of interdependent and interrelated resources, time limitations and persons aimed at achieving specific goals and objectives for the priority areas of science and technology [1].

The aim of this research is to determine the "viability" of innovative projects.

"Viability" in this study refers to the probability of innovative projects will be implemented.

The relevance of the study due to the following factors:

- A large number of innovative projects presented in the various programs;

- The need to determine parameters of the "ideal" innovative project, i.e. such a project, which will be implemented in the future for sure.

The definition of "viability" will give probabilistic predictions about the prospects for the implementation of this innovative project; it will assess the financial risks and other factors related to the innovative project.

The objectives of the study are:

- Description of the innovation project lifecycle;

- Search and analysis of necessary baseline data;

- Search of method for determining the "viability" of the innovation project;

- Assessing of possibility of using this method for the evaluation of "viability".

To evaluate the "viability" of these projects, data of the projects, which participate in Russian programs "UMNIK", "START" and "UMNIK to START", implemented by the Foundation for Assistance to Small Innovative Companies in the scientific and technical sphere are used. Thus, the "viability" can be defined as a likelihood that projects will pass all stages in "UMNIK", 
"START" and "UMNIK to START" programs and subsequently will be successfully implemented. 


\section{Innovative project as an object of study}

\subsection{Description of the innovation project}

The general concept of the innovation project and its life cycle is given in [2]. Main phases of the innovation project lifecycle include:

- Pre-investment phase - performing of various studies for planning innovation project;

- Investment phase - preparation of documentation for the implementation of an innovative project;

- The phase of tenders and contracts - contracts for the supply of various equipment and performance of works are making;

- Phase of the project implementation - plans and schedules of works on the project are developing;

- The final phase of the project - innovative project closes, the launch of the facility and the start of implementation of the product, analyzes the results of the work.

As for the analysis are only available data on the participation of innovative projects in the Russian programs "UMNIK", "START" and "UMNIK to START", in this study under the lifecycle of the innovative project to be understood passage of the project cycle stages of participation in these programs and further implementation.

\section{2 "UMNIK" program}

The "UMNIK" is a federal Russian program to promote the development of youth innovation projects [3]. Only individuals (program focuses mainly on young professionals with no experience in business) participate in the program. The program consists of several stages, presented in Fig. 1.1. 


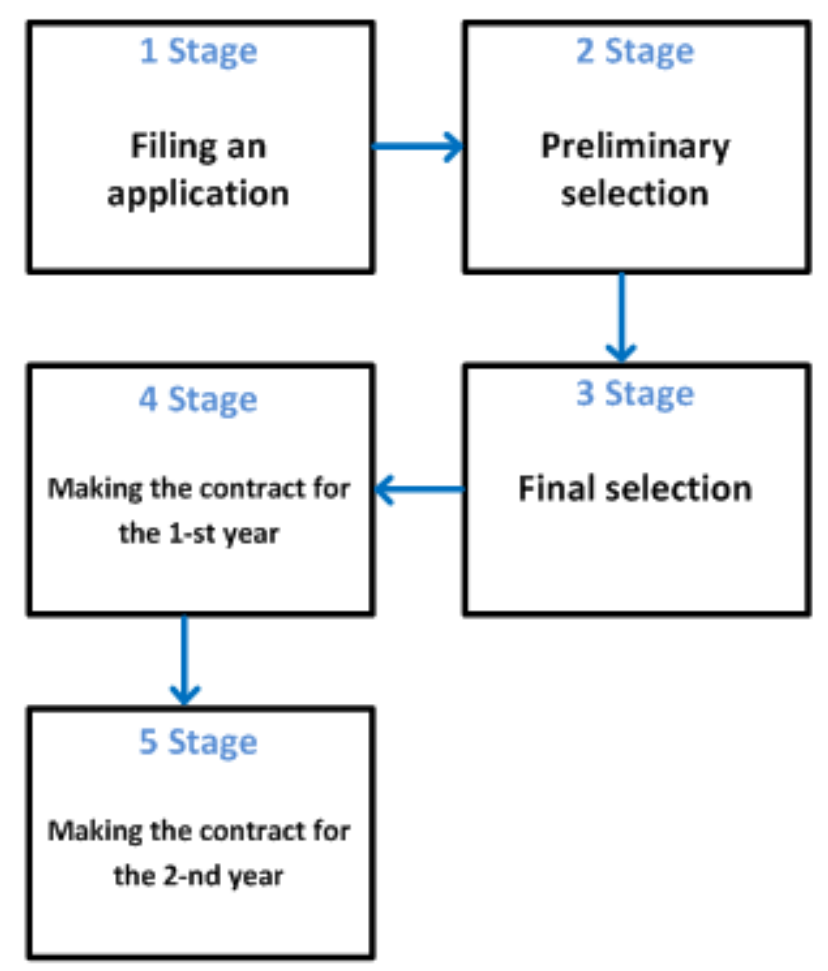

Figure 1.1 - Structure of the program "UMNIK"

To participate in the program one shall submit a request to the organizing committee, which is considered in several stages. Organizing Committee chooses from among the most promising applications and forwards them to the pre-selection. As part of the pre-selection of the applicant is a project in the internal report. As a result of reports of the commission shall decide on the admission of the participant to the next stage or reject the application. The next stage is the final selection, in which the reports are heard preliminary selection of the winners. According to the results of the final selection addressed the issue of providing funding. The winner is awarded a contract with a small innovative company for one year, during which the project is implemented. In the first, the Party shall provide a report on the results of which addressed the issue of the extension of funding for the second year.

\section{3 "START" program}

The program "START" is a federal Russian program to promote the development of small innovative companies [4]. Participate in the program only to legal entities. The structure of the "START" program is presented in Fig. 1.2. 


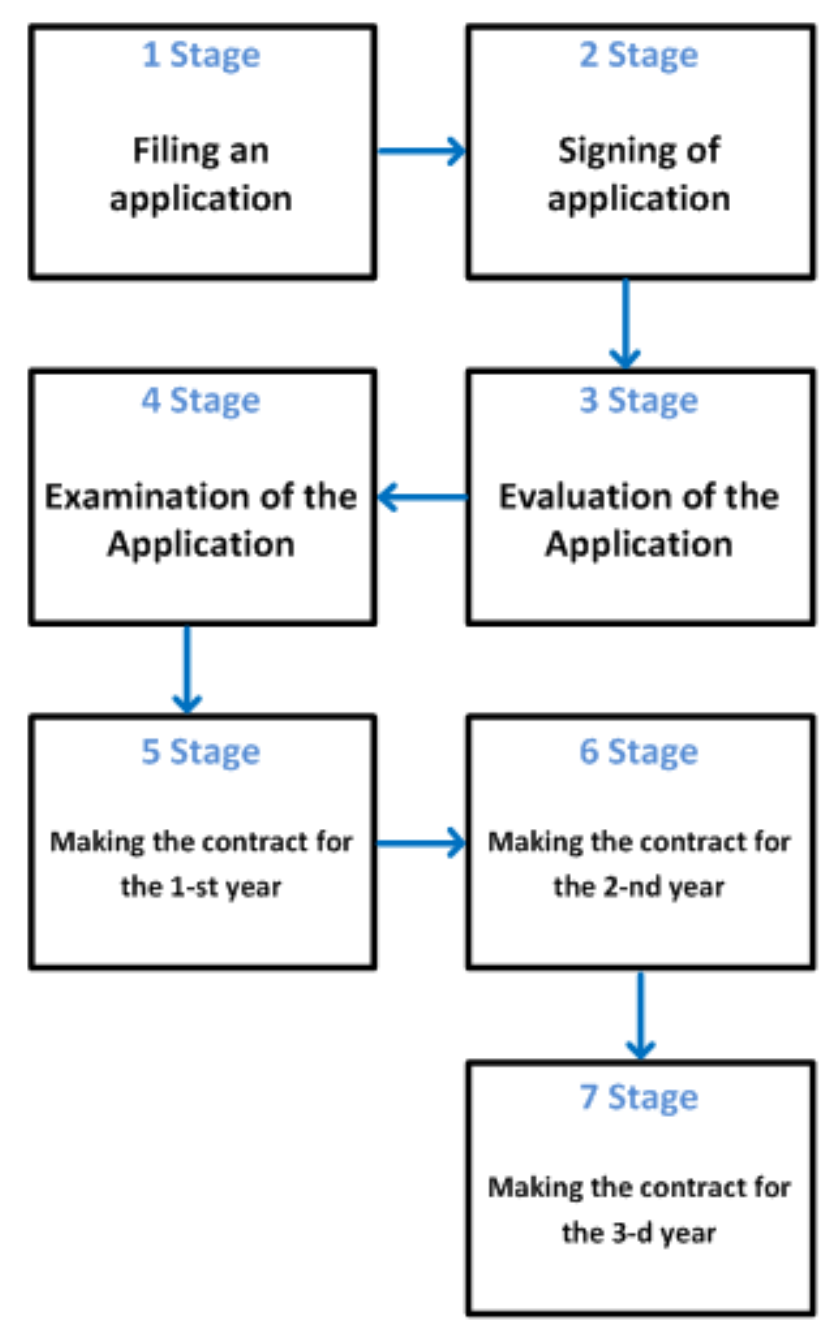

Figure 1.2 - Structure of the program "START"

To participate in the program one shall submit a request to the organizing committee. After that committee considers this request in several stages. Organizing Committee chooses from among the most promising applications and takes them into consideration. This application is no longer available for editing. The next step is the evaluation of the application according to different criteria, application requirements deviate inappropriate. As part of the examination of the application, the Committee shall select the most promising projects for financing, as well as the possibility of holding a full-time hearing, for a more detailed examination of the application. With the project, successfully passed examination of the application is a contract for one year, during which will be further development of the project. In the first year of funding decision is made to continue funding the project, as well as the party attracted extra-budgetary investment for the development of its project for the second year. The result of the second year of the project, a decision to continue 
or refuse funding for a third year.

\section{4 "UMNIK to START" program}

The "UMNIK to START" is a youth innovation projects program, which allows the winners to participate in the "START" program [5]. Participate in the program winners of the program "UMNIK" who are willing to create a small innovative company to participate in the "START" program. Structure "UMNIK to START" program is presented in Fig. 1.3.

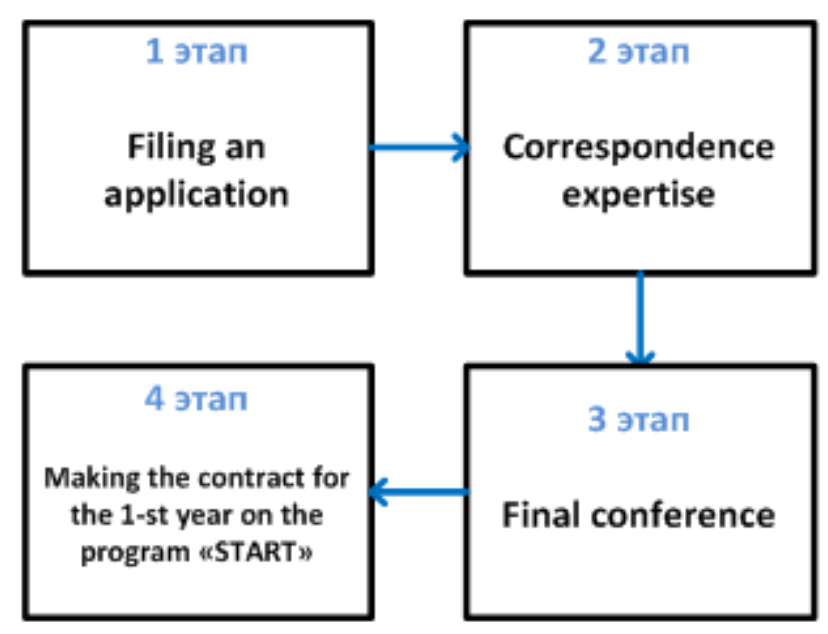

Figure 1.3 - Structure of the program "UMNIK to START"

To participate in the program "UMNIK to START" winners "UMNIK" programs submit an application to the Organizing Committee, considered at several stages. At the stage of the examination of correspondence to select the most promising innovative projects. The decisive step in this program is the final conference, which decision is the conclusion of a contract for the first year of the program "START". 


\section{Search of method for determining the "viability" of the innovative project}

In the course of this Master's research it becomes necessary to search for the method of determining the "viability" of innovative projects. Several methods that can afford to adequately assess the probability of passing of innovative projects at all stages of participation in federal programs ("UMNIK", "START", "UMNIK to START") and further implementation were reviewed.

\subsection{Artificial Neural Networks}

One of the methods considered for the definition of "viability" of innovative projects is the method of artificial neural networks.

Artificial neural network (ANN) - is a system composed of many simple processing elements operating in parallel whose function is determined by the structure of the network, the power of mutual ties and calculations are made in themselves elements or nodes [6, 7].

The brain has a basic property study. For ANN training - is the process of configuring the network architecture and weights of synaptic connections for efficient solutions to the problems. Usually ANN training occurs on a sample. In the process of learning that takes place on some algorithm, the network is responding better and better on the incoming signal.

There are the following methods:

- supervised learning;

- unsupervised learning;

- blended learning.

In the first method, known correct answers to each input examples and the weight will adapt so as to minimize the error. Unsupervised learning allows you to distribute samples categorized by the disclosure of internal structure and nature of the data. In the blended learning combines the above approaches.

\subsection{Genetic algorithms}

Genetic Algorithms (GA) - is algorithms for solving optimization 
problems. For example, such problems can be trained ANN, i.e. the selection of the weight value at which the minimum of errors. In this case, the base basis of the GA is an algorithm random search. The main drawback to a random search is that it becomes unknown how much time to need for finding an answer to this problem. To avoid spending time to solve problems, apply algorithms that have arisen in the biological sciences. In this case, using algorithms that were discovered in the study of evolution and the emergence of new species. It is known that only the fittest can survive in the course of evolution. This leads to the fact that the value of population fitness grows, allowing it more likely to survive in changing conditions $[8,9]$.

\subsection{Markov process}

Random process in some system called a Markov, if the probability of transition of the system to a new state depends only on the state of the system at the moment and does not depend on when and how the system has passed in this state. More details Markov process is considered in [10-14].

In other words, in the Markov process influence throughout history in the process of its future fully focused on the current state of the process.

The main objective of research of Markov processes is to identify probabilities $P_{i}(t), i=0, n$, being process at any time $\mathrm{t}$ in one or another state, which gives full information about a random process. To solve this problem it is necessary:

- Clarification of the conditions in which the process is in the initial time;

- Describe the transitions between states.

Process state at the initial time $\mathrm{t}=0$ is given by the vector of initial probabilities $P(0)=\left\{P_{0}(0), P_{l}(0), \ldots, P_{n}(0)\right\}$.

Markov processes with continuous time transition can be described as a graph or to define a system of differential equations.

To find the end-state probabilities of differential equations are converted into a system of linear equations. 


\subsubsection{Hidden Markov model}

Hidden Markov model (HMM) - a model of the process in which the process is considered to Markov, the unknown, in which state $S_{i}$ of the system (status hidden), but each state $\boldsymbol{S}_{\boldsymbol{i}}$ can with some probability $\boldsymbol{b}_{i o j}$ produce an event $\boldsymbol{o}_{j}$ that can be seen. HMM is described in [15-21].

The transition probabilities between states are described by probability matrix $A=\left\{a_{i j}\right\}$, where $a_{i j}$ - the probability of transition from $i$-th state to $j$-th state. The probability of obtaining each of the $M$ values of the parameters in each of the $N$ states are determined by the vector $B=\left\{b_{j}(k)\right\}$, where $b_{j}(k)$ - the probability of obtaining $k$-th value of the parameter in $j$-th condition. The probability of a given vector of initial states $\pi=\left\{\pi_{i}\right\}$, where $\pi_{i}$ - the probability that the initial time the system is in the $\mathrm{i}$-th state. Thus, the hidden Markov model - a triple $\lambda=\{A, B, \pi\}$.

\subsection{The use of a hidden Markov model relative to federal programs "UMNIK", "START" and "UMNIK to START"}

For visual proof of the applicability of the HMM to participate in innovative projects of federal programs "UMNIK", "START" and "UMNIK to START", construct a model consisting of the programs of stages and transitions between them (Fig. 2.1).

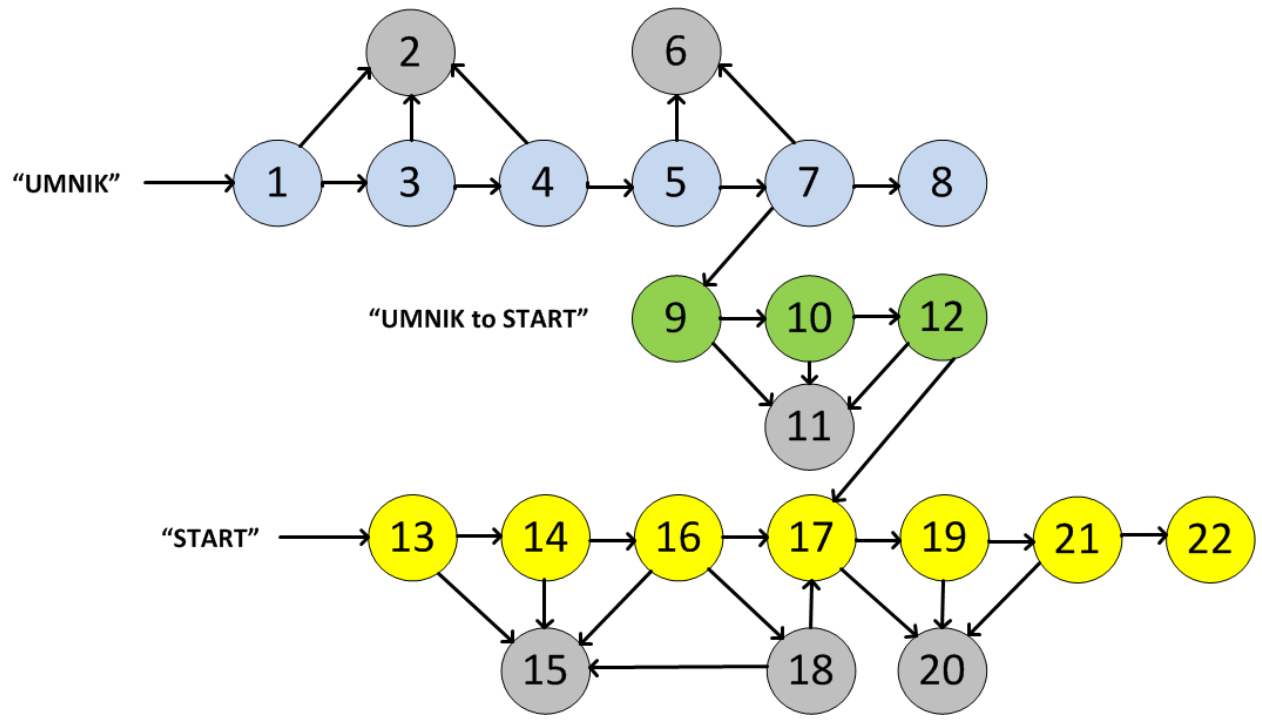

Figure 2.1 - Structure of the HMM for participation IP in a Russian programs 
The states described in the model, based on the stage of the program, described in section 1 .

The program "UMNIK" - states 1-8;

The program "UMNIK to START" - states 9-12;

The program "START" - states 13-22.

\section{States of program "UMNIK":}

1 - Filling an application and appeal to the regional government;

2 - The deviation of the application by the regional government;

3 - Preliminary selection of applications (presentation);

4 - Final selection;

5 - Making the contract with a small innovative company for 1 year (financing);

6 - Termination of R \& D funding;

7 - Making the contract with a small innovative company for 2 year;

8 - Continuation of work on the project.

\section{States of program "UMNIK to START":}

9 - Filing an application;

10 - Extramural expertise;

11 - Deviation of application;

12 - Final conference.

\section{States of program "START":}

13 - Filing an application;

14 - Evaluation of application;

15 - Deviation of application;

16 - Examination of application;

17 - Making the contract for the first year;

18 - Presenting a project;

19 - Making the contract for the second year;

20 - Termination of the contract;

21 - Making the contract for the third year;

22 - Continuation of the work small innovative companies. 
Initially, it is possible to describe only the structure of the Markov model, transition probabilities are unknown. The transition probabilities can be found indirectly by using data on the implementation of the projects.

Based on these determinations, it can be concluded that the model described above can be considered HMM because it contains a finite number of discrete states, the transitions between them take place at regular intervals, and for each possible transition to determine the probability that a constant transition.

\subsection{Search algorithm for finding the unknown parameters of a hidden}

\section{Markov model}

Usually, when working with a hidden Markov model, there are three tasks.

1) Definition of probability of occurrence of a sequence of observations $O$ $=o_{1}, o_{2}, \ldots, o_{T}$ model $\lambda=(A, B, \Pi)$.

2) Selection of chain state $Q=q_{1}, q_{2}, \ldots, q_{T}$ which best fits the available observation sequence $O$, for given $\lambda$ and $O$.

3) Determination of the model parameters $\lambda=(A, B, \Pi)$, ensuring maximum probability $P[O \mid \lambda]$.

In this research, solved the third problem. To solve this problem requires a sequence of input data. Structure of Markov model must be known. It is necessary to determine the initial probability of each state and transition probabilities between states in this model.

To solve this problem use the Baum-Welch algorithm [22-26].

Brief overview of the Baum-Welch algorithm:

For given a set of states: $S=\left\{S_{1}, S_{2}, \ldots, S_{N}\right\}$ and a set of observation symbols: $V=\left\{v_{1}, v_{2}, \ldots, v_{M}\right\}$, model $\lambda=\left(P, O, \pi_{1}\right)$ is defined, where

$P=\left[p_{i, j}\right]$ - Probabilities of state transition;

$O=\left[o_{j}(m)\right]-$ Probabilities of observation;

$\pi_{1}=\left(\pi_{1, i}\right)$ - Initial state probabilities.

Algorithm consists of two steps. At the first step from the known 
parameters of the model probability of being at time $\mathrm{t}$ in state $S_{i}\left(\gamma_{t}(i)\right)$ and probability of being at time $t$ in state $S_{i}$ and at time $t+1$ in state $S_{j}$ given the observation sequence and the model $\left(\xi_{t}(i, j)\right)$ are calculated using following formulas:

$$
\begin{gathered}
(i, j)=\left(q_{t}=S_{i}, q_{t}+1=S_{j} \mid O, \lambda\right) \\
(i)=\Sigma \xi(i, j)
\end{gathered}
$$

At the second step model $\lambda$ are compute based on values $(i), \xi(i, j)$, then re-computing of similarity given and calculated $\lambda$ are performed.

Then the first step is repeated using the calculated. For multiple repetition of this procedure, probability of coincidence the calculation of function with the original one increases. The algorithm converges in the moment when the probability stops changing.

In this research:

Set of states: $S=\left\{S_{1}, S_{2}, \ldots, S_{N}\right\}-$ the state of the program shown in Fig. 2.1;

Set of observation symbols: $V=\left\{v_{1}, v_{2}, \ldots, v_{M}\right\}-$ known data on innovative projects (the number of projects, contracts are made, etc.);

Model $\lambda=\left(P, O, \pi_{1}\right)$.

It is necessary to determine the hidden probability. 


\section{Search and analysis of training data}

\subsection{Search and analysis of the necessary input data}

It is necessary to have input data for training a model in this research. The input data were selected reports the Foundation for assistance development of small companies in the scientific and technical sphere for the years 2010-2013.

Data about total amount of projects participated in the program "UMNIK", amount of projects, which are gone out to the program START and amount of contracts are made on the program UMNIK to START are presented in the Table 3.1.

Table 3.1

Statistical data about projects and contracts of program "UMNIK" during the period 2007-2013

\begin{tabular}{|c|c|c|c|c|c|c|c|}
\hline $\begin{array}{l}\text { Program } \\
\text { UMNIK }\end{array}$ & હ) & ஜ્ఝి & હे & 옥 & $\overline{\bar{\lambda}}$ & ำ & 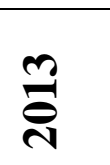 \\
\hline $\begin{array}{l}\text { Amount of } \\
\text { participants }\end{array}$ & 804 & 1037 & 1334 & 1533 & 1910 & 1841 & 1986 \\
\hline $\begin{array}{l}\text { Project, which } \\
\text { are gone over to } \\
\text { the program } \\
\text { START }\end{array}$ & 43 & 48 & 50 & 65 & 61 & 68 & 63 \\
\hline $\begin{array}{c}\text { Amount of } \\
\text { contracts made } \\
\text { on the program } \\
\text { UMNIK to } \\
\text { START }\end{array}$ & - & - & - & - & - & 52 & 68 \\
\hline
\end{tabular}

Data about total amount of projects participated in the program "START" and contracts are made every year on this program are presented in the Table 3.2. 
Table 3.2

Statistical data about projects and contracts of program "START" during the period 2007-2013

\begin{tabular}{|c|c|c|c|c|c|c|c|}
\hline $\begin{array}{c}\text { Program } \\
\text { "START" }\end{array}$ & હે̊ิ & 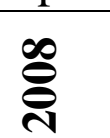 & 옳 & 을 & $\overline{\bar{\nu}}$ & 코ํ & $\stackrel{m}{\stackrel{\text { ก }}{2}}$ \\
\hline $\begin{array}{l}\text { Amount of } \\
\text { applications }\end{array}$ & 1430 & 1480 & 1533 & 2068 & 1812 & 1938 & 1639 \\
\hline $\begin{array}{l}\text { Making the } \\
\text { contract for the } \\
\text { first year }\end{array}$ & 380 & 400 & 450 & 488 & 537 & 495 & 499 \\
\hline $\begin{array}{l}\text { Making the } \\
\text { contract for the } \\
\text { second year }\end{array}$ & 82 & 77 & 63 & 143 & 165 & 177 & 181 \\
\hline $\begin{array}{l}\text { Making the } \\
\text { contract for the } \\
\text { third year }\end{array}$ & 17 & 31 & 27 & 33 & 46 & 71 & 70 \\
\hline
\end{tabular}

Analysis of input data takes place on various parameters, such as:

- The number of submitted and accepted applications for participation in the programs;

- Funding for each program ("UMNIK", "START" and "UMNIK to START");

- The number of applications submitted for each specific topic;

- Features the most successful projects.

The selected data is suited to train the model, but they are not enough for obtaining high-quality results and answer the question about the "viability" of specific projects.

For obtaining of more adequate results need to be introduce additional parameters, such as:

- The implementation of cost;

- The complexity of implementation (Number of people and the number of hours to be spent on project);

- Significance (Evaluation the significance and necessity of the project for the real work). 
In finished form, such data cannot be obtained since a part of them is intellectual property, and the other part is not calculated on a straight statistical authorities. In this regard, it is necessary to calculate this data based on indirect indicators (e.g., macro parameters).

\subsection{Influence criteria of the innovative project at the program stage}

To study the "viability" innovative projects were selected the necessary data for several of the innovative projects from reports the Foundation for Assistance to Small Innovative Enterprises in the scientific and technical sphere for the years 2010-2013.

The criteria required for an adequate analysis of the "viability" of innovative projects are:

- amount of financing;

- number of articles on the subject;

- payback;

- implementation period;

- number of potential customers;

- an operating time over a project;

- number of workers involved;

- research category;

- realization of the region;

- degree of dependence of the project on foreign suppliers and services.

To calculate the probability of influence of the criteria of the innovative project on passage of the program steps ("UMNIK", "START" and "UMNIK to START") and visual presentation, reduce the number of criteria innovative project (Table 3.3). Innovative project design criteria used for analysis:

- amount of financing (1);

- $\operatorname{payback}(2)$;

- implementation period (3);

- number of articles on the subject (4); 
- number of potential customers (5).

Table 3.3 - Data from a sample and a reduced number of criteria IP

\begin{tabular}{|c|c|c|c|c|c|c|c|c|c|c|}
\hline $\begin{array}{c}\text { Criteria of the IP } \\
\text { / IP }\end{array}$ & $\mathbf{1}$ & $\mathbf{2}$ & $\mathbf{3}$ & $\mathbf{4}$ & $\mathbf{5}$ & $\mathbf{6}$ & $\mathbf{7}$ & $\mathbf{8}$ & $\mathbf{9}$ & $\mathbf{1 0}$ \\
\hline $\begin{array}{c}\text { Amount of } \\
\text { financing }\end{array}$ & 200 & 150 & 300 & 280 & 120 & 90 & 700 & 160 & 60 & 350 \\
\hline Payback & 140 & 120 & 150 & 300 & 130 & 200 & 400 & 250 & 330 & 280 \\
\hline $\begin{array}{c}\text { Implementation } \\
\text { period }\end{array}$ & 0,5 & 1 & 1 & 2 & 2 & 2 & 1 & 1,5 & 1,5 & 1 \\
\hline $\begin{array}{c}\text { Number of } \\
\text { articles on the } \\
\text { subject }\end{array}$ & 3 & 2 & 4 & 5 & 3 & 0 & 4 & 3 & 2 & 1 \\
\hline $\begin{array}{c}\text { Number of } \\
\text { potential } \\
\text { customers }\end{array}$ & 7 & 4 & 3 & 1 & 1 & 1 & 2 & 2 & 3 & 5 \\
\hline
\end{tabular}

The next step is to assess the impact of each criterion on the steps of passing the stages of innovative project programs ("UMNIK", "START", UMNIK to START "). For a more adequate assessment of the impact of the criteria, combine similar stages of programs. As a result, for the assessment, there are three most important stages (Fig. 3.1):

- probability of approval of the application IP;

- probability of passing IP selection steps in a specific federal program;

- probability of successful participation in a specific IP federal program.

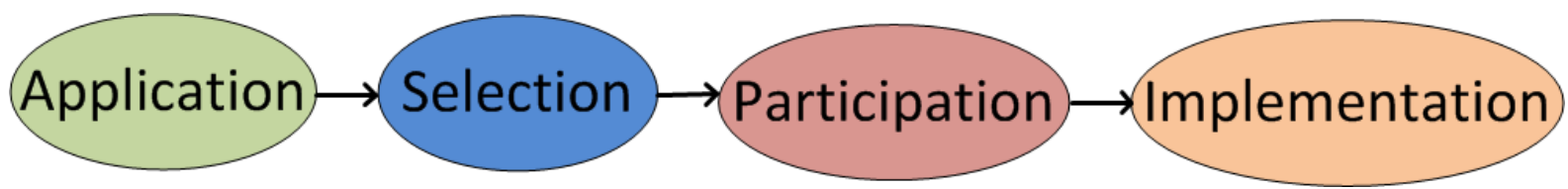

Figure 3.1 - Steps of passage IP federal programs

Estimate impact of each criterion for passing stages innovative project of federal programs. 


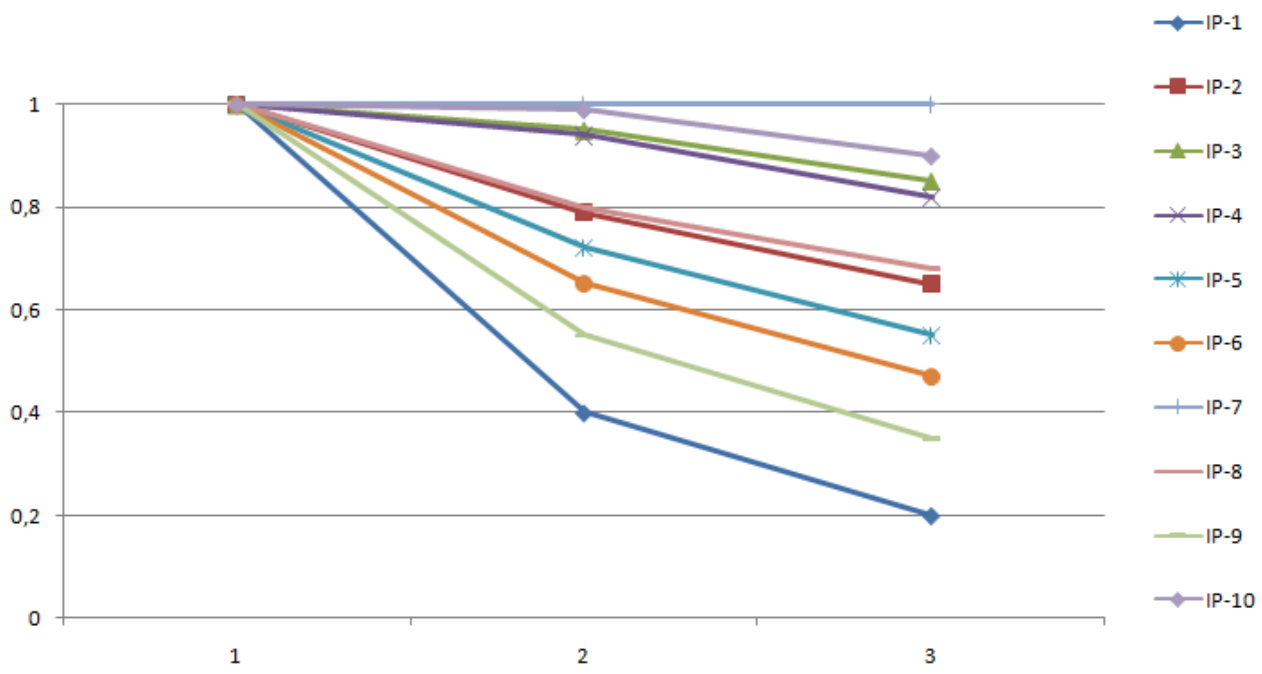

Figure 3.2 - Impact of the first criterion for passing the stages of the innovation project of federal programs

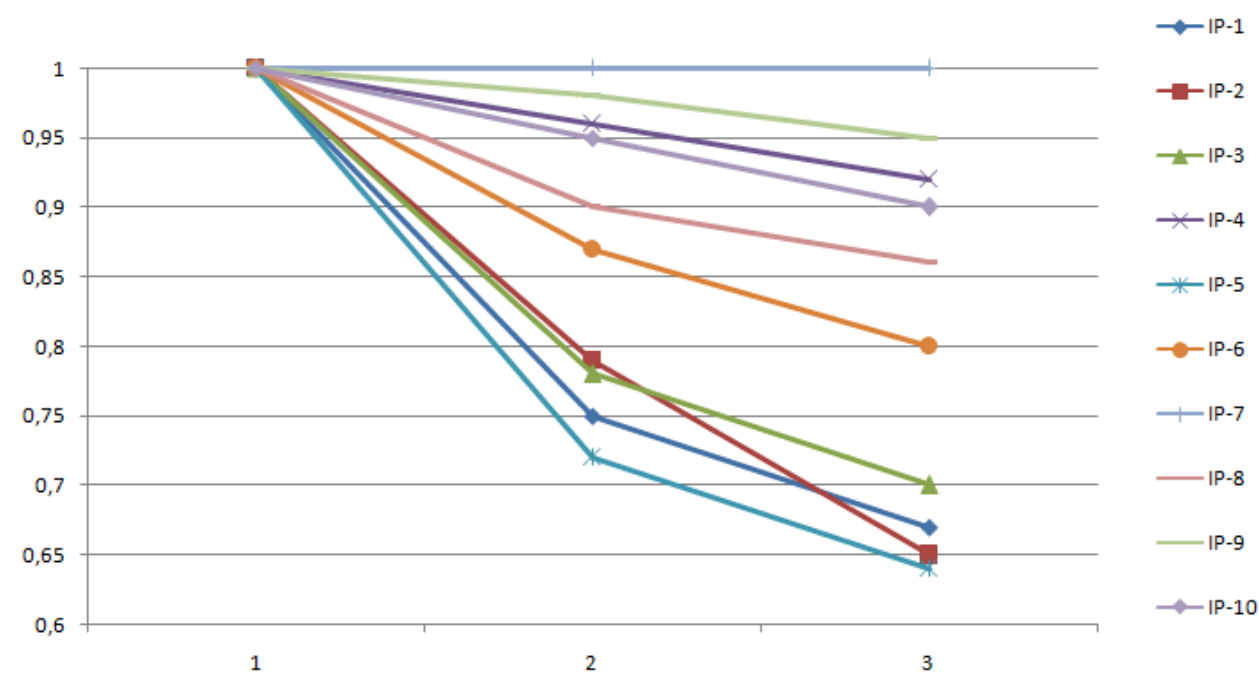

Figure 3.3 - Impact of the second criterion for passing the stages of the innovation project of federal programs

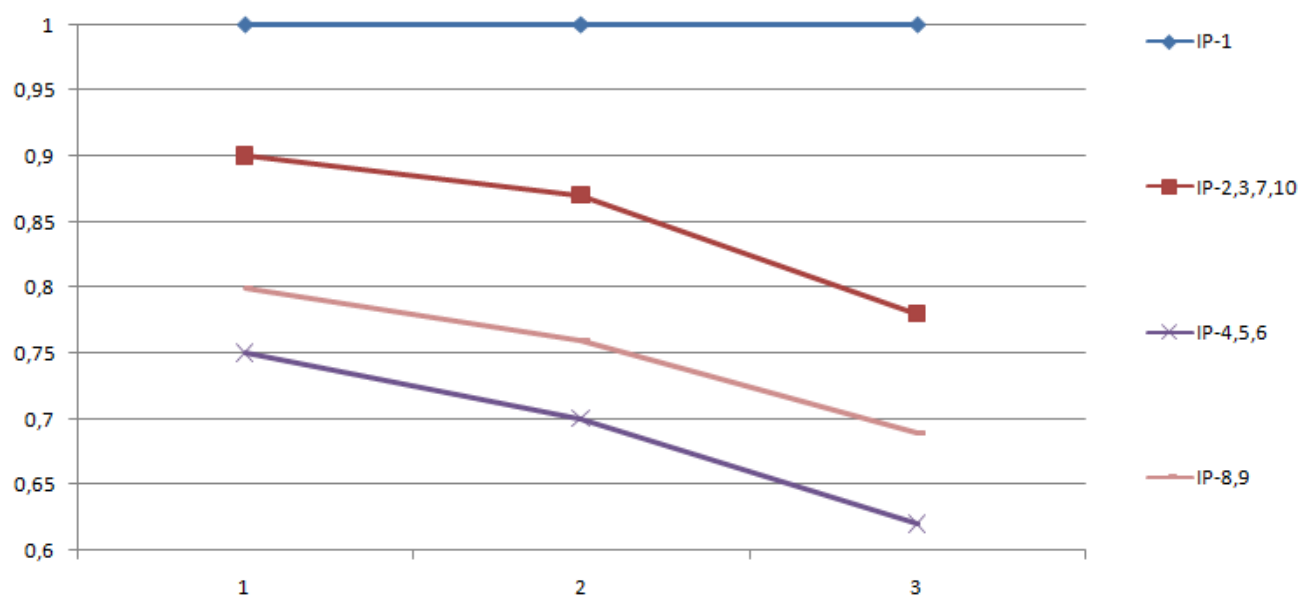

Figure 3.4 - Impact of the third criterion for passing the stages of the innovation project of federal programs 


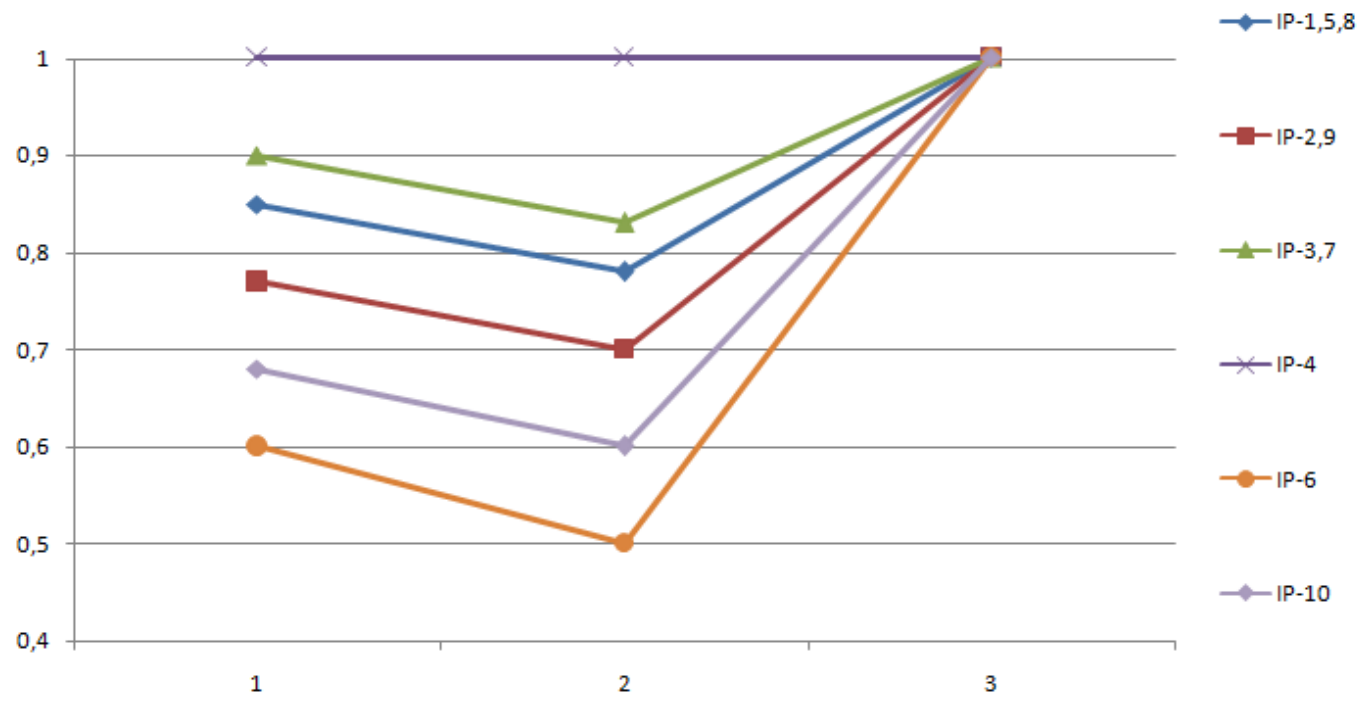

Figure 3.5 - Impact of the fourth criterion for passing the stages of the innovation project of federal programs

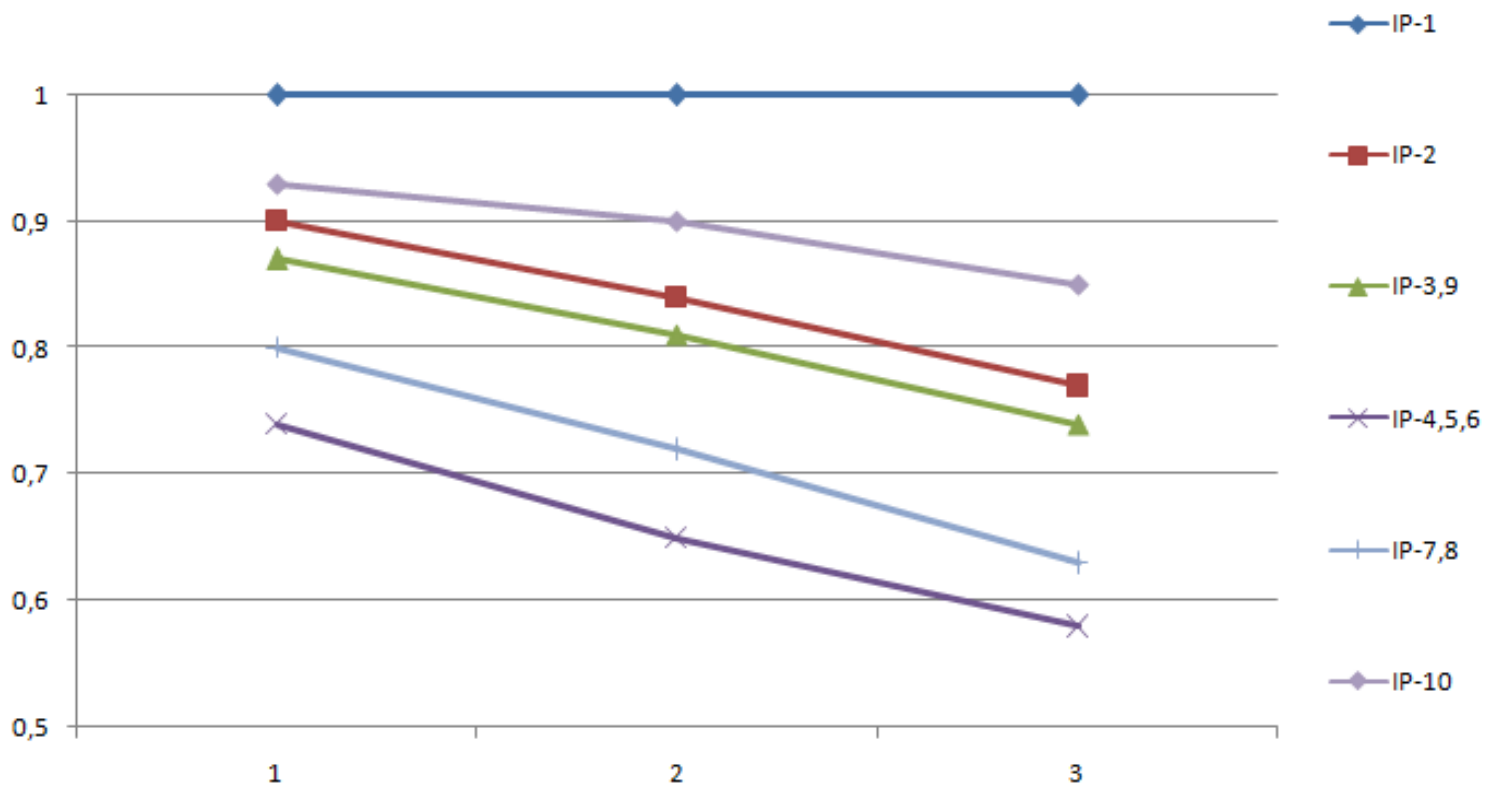

Figure 3.6 - Impact of the fifth criterion for passing the stages of the innovation project of federal programs

To determine the criteria, have the greatest impact at every stage of the innovation project of participation in federal programs, it is necessary to estimate the probability of passage of each stage of the innovation project with its data values for each criterion. 


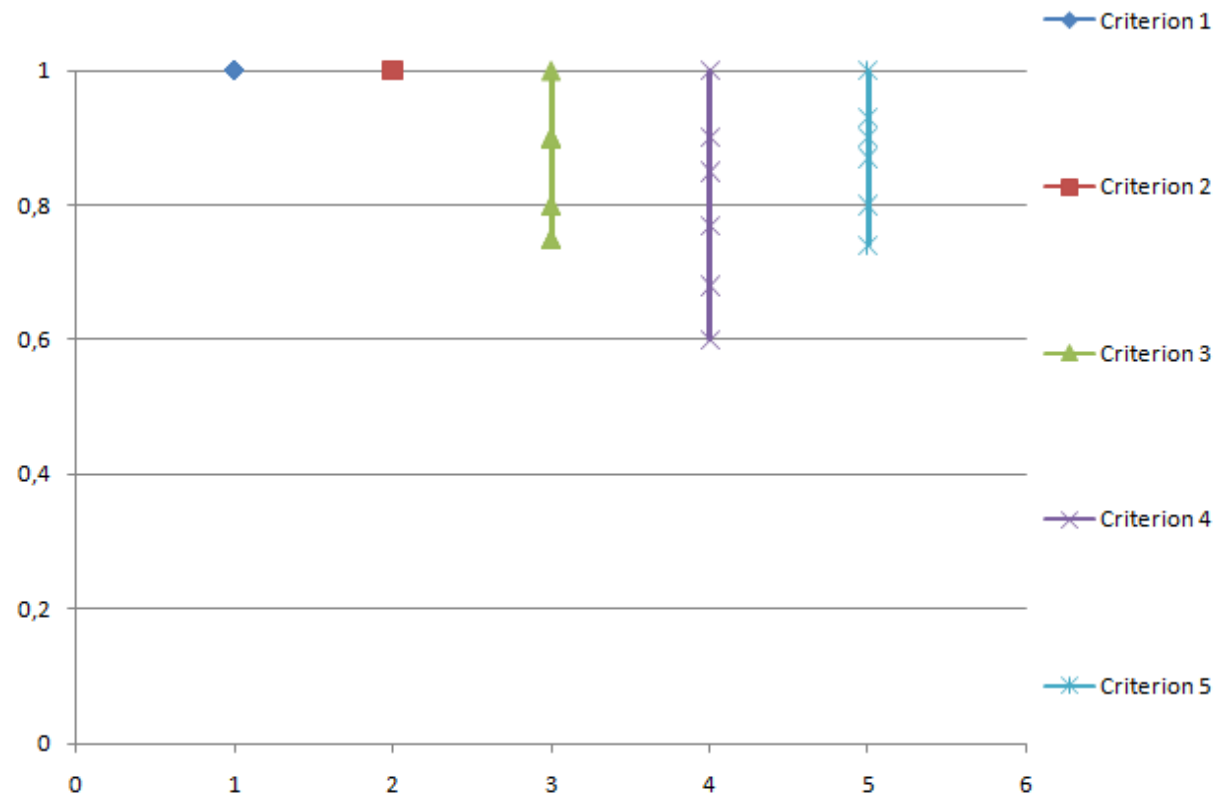

Figure 3.7 - Degree of influence the criteria of the innovative project on the application stage

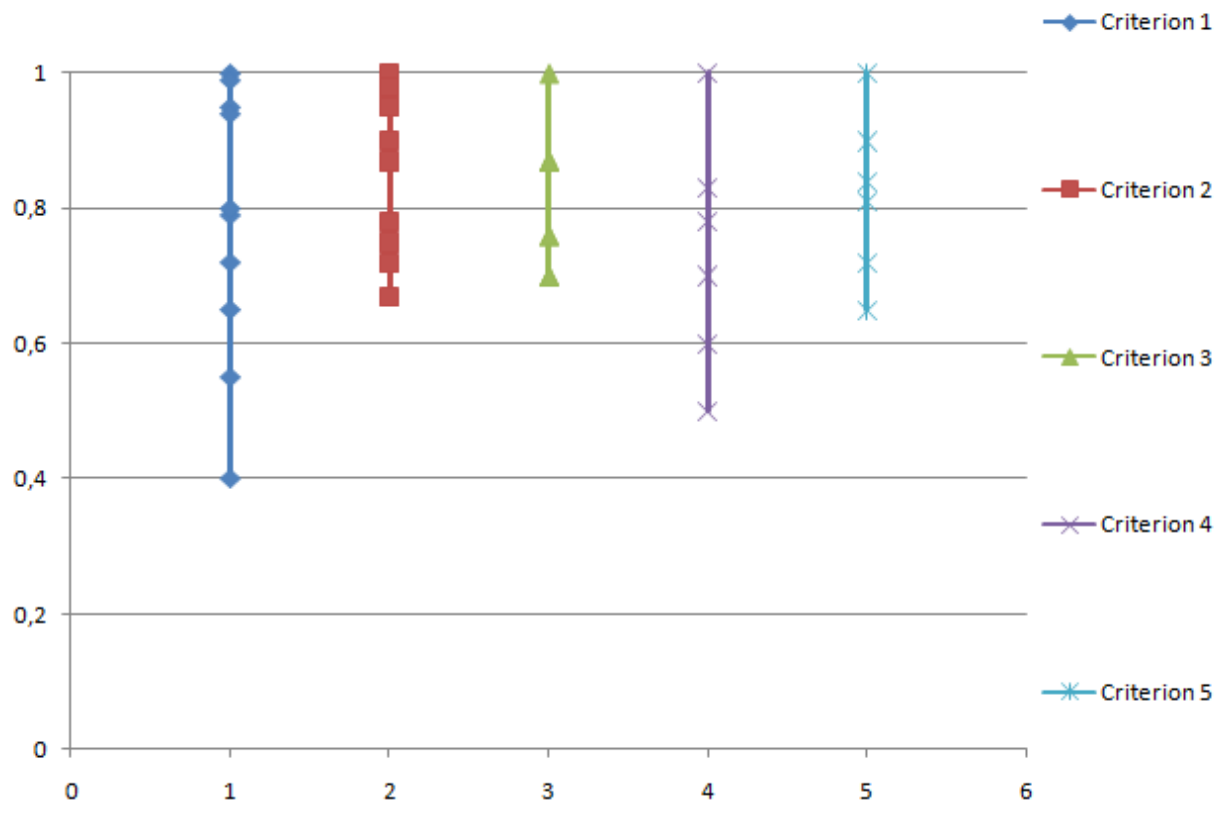

Figure 3.8 - Degree of influence the criteria of the innovative project on the selection stage 


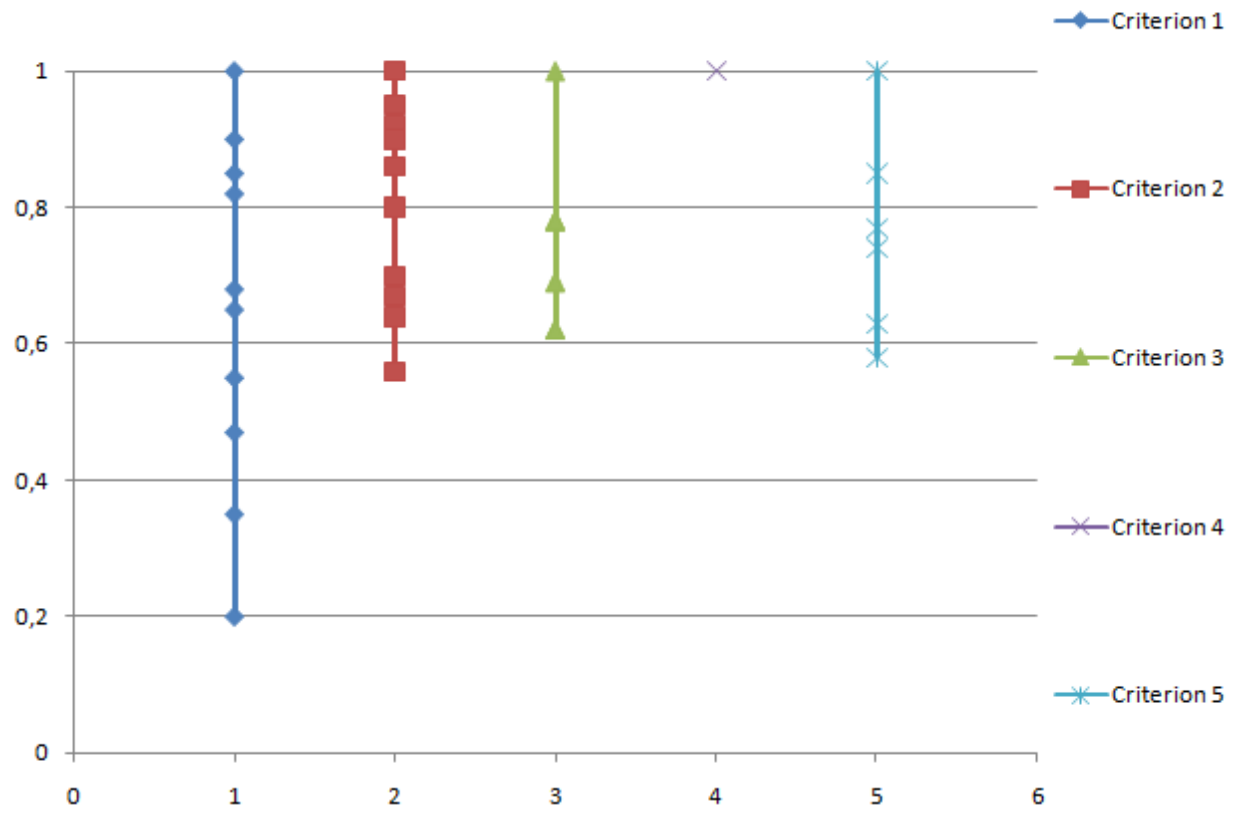

Figure 3.9 - Degree of influence the criteria of the innovative project on the participation stage

Based on the above impact analysis and assessment of each criterion on the steps of passage IP federal programs stages, concludes that "the ideal IP", i.e. such a project, which will surely be implemented. 


\section{Practical implementation of the Markov model and the calculation of "viability" of innovation projects}

In the Master's studies necessary to implement HMM in one of the software packages. Implementation of the HMM should assume the existence of states, in this case, steps IP participation in Russian federal programs. It is also necessary to have the transition probabilities between the states, which are initially unknown. The program is to be implemented, should meet the following conditions:

- training and re-training model;

- prediction of known probabilities for the "new" IP.

In the first stage training model will be implemented on the basis of a statistical sample IP. IP data will have different statistics for each of the criteria. Retraining the model will be the addition of new statistical data to the original HMM, thus will increase the accuracy of prediction of the unknown probabilities for the prediction phase.

The second step in the HMM model loading criteria for the "new" IP ("new" is called the IP, which was not involved in the statistical sample at training model). After downloading the information about the "new" IP in the HMM is a calculation of unknown probability of transition between states with the help of a trained model and algorithm, the Baum-Welch. In the prediction of unknown transition probabilities between the states of the model, the graph is observed iterative process between the unknown parameters computed BaumWelch algorithm to convergence. After the convergence of these parameters, recalculation of unknown probability "new" IP stop at a certain value, which will be the predicted probability of of passage IP of a phase of its implementation.

\subsection{Preparation of the Markov model}

To build a more appropriate model, reduce the number of states of Markov model (Fig. 4.1): 


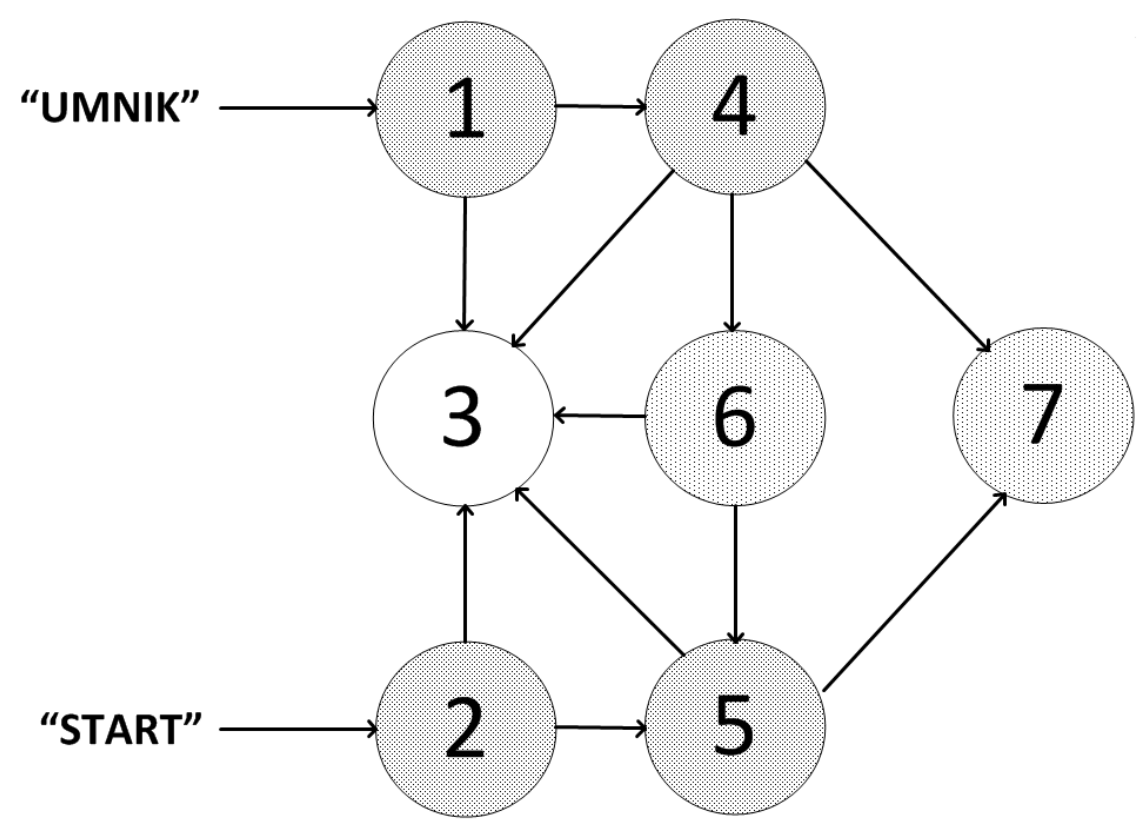

Figure 4.1 - Structure of the Markov model

Description of states of the model:

1 - Filing of the application and the selection of the program "UMNIK";

2 - Filing applications and selection of the program "START";

3 - Rejection of the application or the end of the project to participate in the program;

4 - Participation in the "UMNIK" program;

5 - Participation in the program "START";

6 - Filing of the application and the selection of the program "UMNIK START";

7 - Implementation of the project.

In practice, a reduced number of states turned great anyway, so it is necessary to re-state reduction.

After analyzing the available statistical data and the existing state sets the program: "UMNIK", "START" and "UMNIK to START", conclude that for the first version of the algorithm implementation Baum-Welch and calculate hidden probably be enough only four states (Fig. 4.2 ):

- filing an application SP;

- IP selection;

- IP participation in the federal program; 
- IP implementation

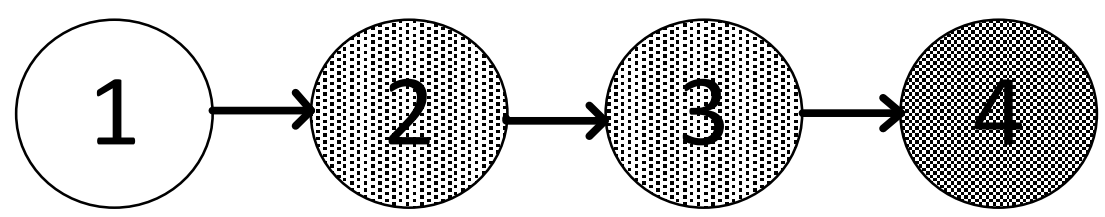

Figure 4.2 -Basic steps (state) cycle IP in federal programs

Description of states of the model:

1 - filing the application IP on a particular federal program;

2 - selection stage IP on a specific federal program;

3 - IP participation in a specific federal program;

4 - IP implementation.

In this model is necessary to determine the transition probabilities between the hidden states. Such probability is:

- probability of approval of the application, SP;

- probability of passing IP selection steps in a specific federal program;

- probability of successful participation in a specific IP federal program.

\subsection{Implementation of Markov model}

Construction of HMM and the calculation of the unknown probabilities is implemented in the software package MATLAB [27-30].

First need to train the HMM on the basis of available statistical sampling on several IP involved in the Russian federal programs, "UMNIK", "START" and "UMNIK to START".

After training HMM necessary predict the unknown transition probabilities for the "new" IP-based algorithm, the Baum-Welch (Fig. 4.3).

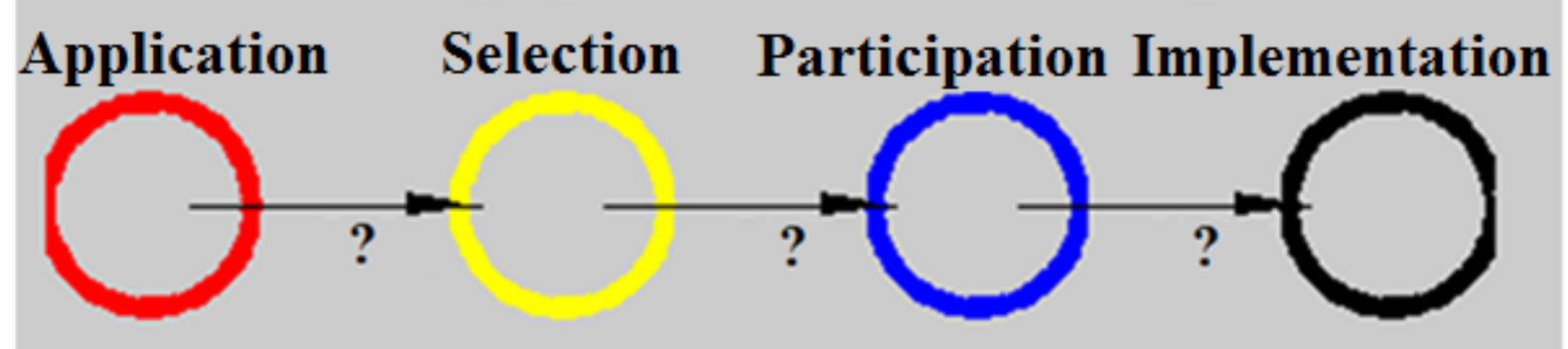

Figure 4.3 - Detail of the implementation of the algorithm from MATLAB In the application stage is fed statistical sample consisting of several IP 
and HMM learning takes place. This method of learning is called - supervised learning.

After training HMM, load the desired IP and observe algorithm iterations of Baum-Welch. After several iterations, the algorithm converges, and the transition probabilities between states are unchanged (Fig. 4.4, 4.5). This method of learning is called - unsupervised learning.

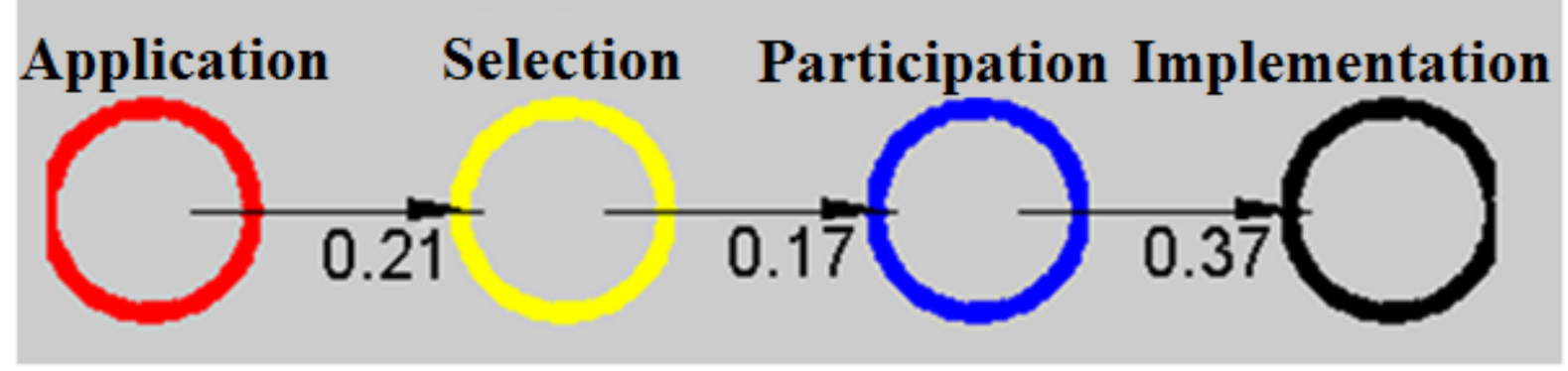

Figure 4.4 - Predicted probabilities of state transition to the "new" IP

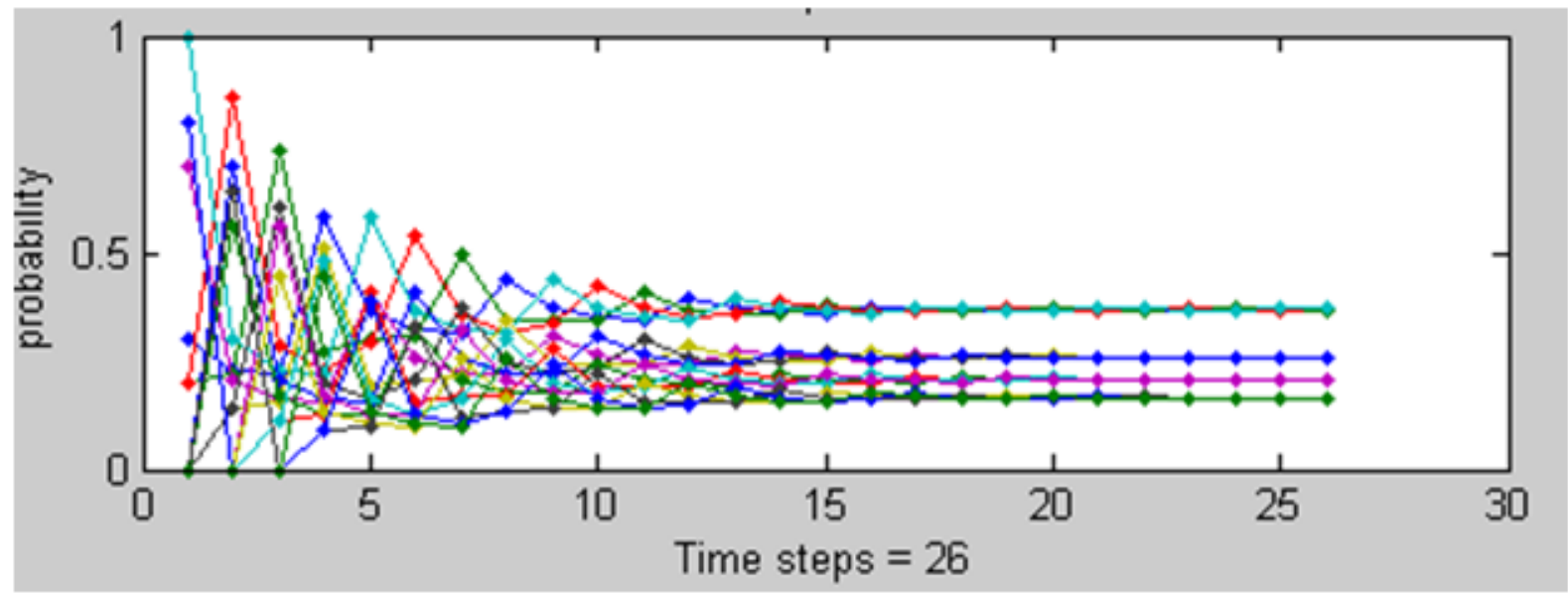

Figure 4.5 - The iterations of the Baum-Welch algorithm

In Figure 4.5 it is clear that the "new" IP algorithm iterations of BaumWelch converged about, on the twentieth computing step.

Thus, it is concluded that the use of the HMM and the Baum-Welch algorithm is applicable to the analysis of "viability" IP. 


\section{Closing}

In the study has been described an innovative project and its life cycle, have also been described Russian federal program "UMNIK", "START" and "UMNIK to START".

Various methods for the analysis of "viability" innovative projects were considered. Of the methods considered Markov Models method has been chosen as the method takes into account the initially character Markovski innovation project lifecycle. It was found that the method of hidden Markov models applied to the problem of the definition of "viability" of innovative projects.

Hidden Markov model was developed to describe all the stages and transitions between Russian federal programs "UMNIK", "START" and "UMNIK to START".

As a method of solving algorithm was proposed the Baum-Welch. Assumptions and limitations necessary for its implementation have been identified.

Analyzed the influence of the criteria of the innovative project at the stage of the passage of the federal programs "UMNIK", "START" and "UMNIK to START". And also analyzed the most important criterion of an innovative project for each program stage.

During the implementation of the Baum-Welch algorithm, hidden Markov model in the software MATLAB complex was built. This model has been trained on a sample of innovative projects. Further it was predicted unknown (hidden) the transition probability between the states of the programs for a "new" innovative project.

The definition of "viability" will give probabilistic predictions about the prospects for the implementation of innovative projects and will assess the financial risks and other factors related to their implementation. 


\section{List of reference}

1. Osnovy innovacionnogo menegmenta: Teoriya i praktika: Uchebnoe posobie / Pod redakciei. P.N. Zavalina - M.: JSC Ekonomika », 2000. - 475s. (In Russian)

2. Adizes I. Corporate lifecycles: how and why corporations grow and die and what to do about it / I. Adizes, Englewood Cliffs, N.J.: Prentice Hall, 1988

3. Russian federal program "UMNIK". [Online]. Available at: http://www.fasie.ru/programs/programma-umnik/ (accessed 9 February 2016).

4. Russian federal program "START". [Online]. Available at: http://www.fasie.ru/programs/programma-start/ (accessed 9 February 2016).

5. Russian federal program "UMNIK to START". [Online]. Available at: http://www.nauka-nov.ru/fsrmpnts/665/ (accessed 9 February 2016).

6. Surovcev I.S., Klukin V.I., Pivovarova R.P. Neyronnie seti. Voronezh: VGU, 1994. — 224p. (In Russian)

7. Caudill, M.,Neural Networks Primer,San Francisco, CA: Miller Freeman Publications, 1989.

8. Gladkov L.A., Kureychik V.V., Kureychik V.M. Geneticheskie algoritmy: Uchebnoe posobie - 2-e izdanie - M: Fizmalit, 2006. - S. 320. (In Russian)

9. Skobcov U.A. Osnovy evolucionnyh vychisleniy - Doneck: DonNTU, 2008. - S.326. (In Russian)

10. Markovskie processi / Portenko N.I., Skorohod A.V., Shurenkov V.M. - 1989. - 765 s. (In Russian)

11. Dub Dzh. L. Veroyatnostnie processy. - M.: IL, 1956.

12. Osnovaniya teorii Markovskih processov / Dynkin E.B. - Moskva: FIZMALIT,1992. - 228 s. (In Russian)

13. Sevastyanov B.A. O nekotorih tipah markovskih processov. - UMN, 1949, t. 4, vypusk. 4, s. 194. (In Russian) 
14. Kalinkin A.BV Structura mnozhestva markovskih processov. Vestnik RUDN, seria "Prikladnaya matematika i informatika", 1998, vypusk. 1, cs 93-103. (In Russian)

15. Elms A.J., Procter S., Illingworth J. The advantage of using an HMMbased approach for faxed word recognition// International Journal on Document Analysis and Recognition (1998) 1: 18-36

16. Elliott R. J., Aggoun L., Moore J. B. Hidden Markov models: Estimation and control. — Berlin: Springer-Verlag, 1995.

17. Gmurman V.E., Teoriya veroyatnostey i matematicheskaya statistika, M.: Vyisshee obrazovanie. 2005 (In Russian)

18. Kelbert M. Ya., Suhov Yu. M. Veroyatnost i statistika v primerah i zadachah, tom II: markovskie tsepi kak otpravnaya tochka teorii sluchaynyih protsessov i ih prilozheniya. - M: Izdatelstvo MTsNMO, 2009. - 571 s. (In Russian)

19. Yang J., Xu Y. Hidden Markov Model for Gesture Recognition: Technical Report CMURI-TR-94-10. - Pittsburgh, PA: Carnegie Mellon Univ., Robotics Institute, 1994. - $27 \mathrm{p}$

20. Wang X., Xia M., Cai H., Gao Y., Cattani C. Hidden-Markov-modelsbased dynamic hand gesture recognition // Math. ProblemsEng. - 2012. - V. 2012. - P. 986134-1- 986134-11.

21. Rabiner L.R. Skryityie Markovskie modeli i ih primenenie v izbrannyih prilozheniya pri raspoznavanii rechi. M.: TIIER,t.77, \#2, fevral 1989 - s. 20-86. (In Russian)

22. Geoffrey McLachlan and Thriyambakam Krishnan. The EM Algorithm and Extensions. JohnWiley\&Sons, NewYork, 1996.

23. Jeff A. Bilmes. A gentle tutorial of the EM algorithm and its application to parameter estimation for gaussian mixture and hidden markov models. Technical Report TR-97-021, U. C. Berkeley, April 1998.

24. Forney G.D., Viterbi algorithm. M.: IEEE, т.61, №3, c.268-276, 1973 25. Moss L., Baum-Welch algorithm. M.: Q520, Rawles Hall, 2008 
26. Welch L. Hidden Markov Models and the Baum-Welch algorithm // IEEE Information Theory Society Newsletter, 2003.

27. S.P. Iglin Teoriya veroyatnostey i matematicheskaya statistika na baze MATLAB. Harkov: NTU "HPI", 2006,-612 str. (In Russian)

28. S.D. Shtovba Proektirovanie nechetkih sistem sredstvami MATLAB. M.: Goryachaya Liniya - Telekom, 2007,-288 str. ISBN: 5-93517-359-X. (In Russian)

29. Yu. Minaev, O. Filimonova, Benameur Lies. Metodyi i algoritmyi resheniya zadach identifikatsii i prognozirovaniya $\mathrm{v}$ usloviyah neopredelennosti v neyrosetevom logicheskom bazise. M.: Goryachaya liniya — Telekom, 2003. (In Russian)

30. Yu. Ketkov, A. Ketkov, M. Shults. MATLAB 6.x: programmirovanie chislennyih metodov. C-Pb.: BHV-Peterburg, 2004. (In Russian) 